\title{
Comparison of Surgery and Prolonged Spironolactone Therapy in Patients with Hypertension, Aldosterone Excess, and Low Plasma Renin
}

\author{
J. J. BROWN, D. L. DAVIES, J. B. FERRISS, R. FRASER, E. HAYWOOD, A. F. LEVER,
} J. I. S. ROBERTSON

British Medical Fournal, 1972, 2, 729-734

In addition to its routine preoperative use, spironolactone can now be advised as long-term therapy in selected

Summary

The effect of prolonged preoperative treatment with spironolactone has been studied in a series of 67 patients with hypertension, aldosterone excess, and low plasma renin. In the series as a whole a highly significant reduction in both systolic and diastolic pressures was achieved, with no evidence of escape from control during therapy lasting several years in some cases. The drug was equally effective in controlling blood pressure in patients with and without adrenocortical adenomata. Occasional unresponsive patients were encountered in both groups; pretreatment blood urea levels in these were significantly higher than in the responsive patients. The hypotensive effect of spironolactone usually predicted the subsequent response to adrenal surgery.

Spironolactone in all cases corrected plasma electrolyte abnormalities; significant increases in total exchangeable (or total body) potassium and significant reductions in total exchangeable sodium, total body water, extracellular fluid, and plasma volumes were seen. Plasma urea rose during treatment and there was a slight fall in mean body weight. Significant increases in peripheral venous plasma renin and angiotensin II concentrations occurred during treatment.

In two patients no increase in aldosterone secretion rate was found during treatment, although plasma aldosterone rose in three of four subjects studied.

Severe side effects were rare; in only two of the 67 patients did the drug have to be stopped.

Medical Research Council Blood Pressure Unit and University Department of Medicine, Western Infirmary, Glasgow W.1 J. J. BROWN, M.B., F.R.C.P., Honorary Consultant Physician

D. L. DAVIES, M.B., M.R.C.P., Lecturer in Medicine

J. B. FERRISS, M.B., M.R.C.P., Medical Registrar

R. FRASER, M.Sc., PH.D. Member of Scientific Staff

E. HAYWOOD, M.R.A.C.P., Visiting Research Worker (Present address:

Department of Medicine, University of Western Australia, Perth, Western Australia)

A. F. LEVER, M.B., F.R.C.P., Honorary Consultant Physician

J. I. S. ROBERTSON, M.B., F.R.C.P., Honorary Consultant Physician patients.

\section{Introduction}

The acute effects of treatment with steroidal lactones (spirolactones) in patients with aldosterone-secreting adenomata were reported soon after the drugs became available (Bolte et al., 1958; Conn et al., 1958; Salassa et al., 1958; Kistler et al., 1959; Bartter, 1960). Flanagan et al. (1962) and Mobley et al. (1962) described a fall in arterial pressure together with correction of serum electrolyte abnormalities during therapy lasting up to 10 weeks.

Brown et al. (1963a, 1964a, 1964b, 1965) studied the effect of more prolonged medication, demonstrating the maintenance of normal plasma and total exchangeable values of sodium and potassium, correction of expanded total body water, plasma and extracellular fluid volumes, and reduction of blood pressure in several patients treated for periods up to $10 \frac{1}{2}$ months. These beneficial results of long-term therapy have been amply confirmed (Spark and Melby, 1968; Brown et al., 1968c, 1969a, 1969b, 1970b, 1970c, 1971a, 1971b; Crane and Harris, 1970; Morimoto et al., 1970; Tarazi et al., 1970).

The present paper describes the results of prolonged treatment with spironolactone before operation in a series of 67 patients with hypertension, aldosterone excess, and low plasma renin. The effect of the drug in correcting the hypertension and biochemical abnormalities has been studied in subjects variously with and without adrenocortical adenomata. A comparison with the results of subsequent adrenal surgery in both groups of patients has also been made.

\section{Patients and Methods}

The 67 patients ( 41 women, 26 men) studied were aged 18 to 67 years. All presented with raised arterial pressure (range $260 / 160$ to $150 / 103 \mathrm{~mm} \mathrm{Hg}$; mean 201/122 $\pm 24 / 12$ S.D.). All had abnormally high concentrations of aldosterone in peripheral venous plasma (greater than $18 \mathrm{ng} / 100 \mathrm{ml}$ ) on at least one occasion; three were also shown to have raised aldo- 
sterone secretion rates $(500 \mu \mathrm{g} / 24$ hours or higher). Plasma renin concentration was below the normal mean of 8.4 units/l. on at least one occasion in every case, and below the normal range of 4-20 units/1. at least once in 51 of the 67 patients. In three subjects plasma angiotensin II was also measured and shown to be subnormal or low (range $2-8 \mathrm{pg} / \mathrm{ml}$; normal range 5-35 $\mathrm{pg} / \mathrm{ml}$ ). In none of the 67 patients was plasma 11-hydroxycorticosteroid concentration or the response to intramuscular corticotrophin abnormal, and in none was the urinary excretion of 17-ketogenic steroids increased.

The initial studies in 22 of the 67 were performed in the medical unit, St. Mary's Hospital, London, and in the remaining 45 in the Medical Research Council Blood Pressure Unit, Western Infirmary, Glasgow. Biochemical data of in-patients were obtained while the subject received either a diet of fixed known normal potassium and sodium content (Na 120-140; $\mathrm{K} 50-70 \mathrm{mEq}$ ) (35 cases) or a normal ward diet. No dietary restriction was imposed when the patients left hospital. No patient had received diuretic drugs, potassium supplements, oral contraceptives, or liquorice preparations (see Brown et al., 1971a, 1971c, 1972d) for at least four weeks before any of the investigations reported here.

Since lower arterial pressures may be obtained in some patients when in the ward as compared with the outpatient clinic (see Pickering, 1968), all the blood pressure readings used in the analysis, whether before or during treatment, were those taken in the outpatient department with a standard sphygmomanometer, with the patient seated. No hypotensive agents other than spironolactone were given.

Whenever possible, readmission to this unit was arranged for further assessment after the start of treatment. However, since many patients were originally referred from distant centres this was not always possible, and data were then abstracted from the relevant local hospital case-records.

Plasma (or serum) electrolytes and urea were estimated by standard techniques in the routine biochemistry laboratory. Although for reasons discussed elsewhere (Brown et al., 1970a) plasma is preferable to serum for potassium measurement, plasma and serum potassium levels have been assessed together in the present work. Forearm exercise was avoided during venopuncture to obviate this cause of falsely high plasma potassium values (Brown et al., 1968a, 1970a).

Blood pressure and electrolyte and urea measurements made up to the fourth week following surgery or the start of spironolactone were disregarded; all otherwise valid available data have been included here. Every individual was not necessarily seen at each follow-up interval (see Figs. 1-3).

Total exchangeable sodium $\left(\mathrm{Na}_{\mathrm{E}}\right)$, total exchangeable potassium $\left(\mathrm{K}_{\mathrm{E}}\right)$, extracellular fluid volume, total body water, and plasma volume were measured by the principle of isotope dilution as previously reported (Brown et al., 1965, 1968b), the respective isotopes being ${ }^{24} \mathrm{Na},{ }^{42} \mathrm{~K},{ }^{82} \mathrm{Br},{ }^{3} \mathrm{H}$, and ${ }^{181} \mathrm{I}$. ${ }^{4} \mathrm{~K}$ was used for the estimation of $\mathrm{K}_{\mathrm{E}}$ in five patients (D. $\mathrm{L}$. Davies and J. W. K. Robertson, unpublished). In three subjects total body potassium $\left(\mathrm{K}_{\mathrm{T}}\right)$ was measured by estimating endogenous ${ }^{\circ} \mathrm{K}$ as described by Boddy (1967). The body weights reported during treatment are those obtained between 1 and 12 months after starting spironolactone.

Plasma renin concentration was measured by the method of Brown et al. (1964c), plasma angiotensin II by radioimmunoassay (Düsterdieck and McElwee, 1971), plasma aldosterone by the method of Fraser and James (1968), and aldosterone secretion rate as described by Cope et al. (1961).

Statistical calculations were performed with a HewlettPackard 9810A desk computer.

\section{Results}

\section{RENIN-ALDOSTERONE RELATION BEFORE TREATMENT}

Before starting spironolactone therapy a statistically significant inverse relation was found between concurrent plasma renin and plasma aldosterone concentrations $(r=-0.218 ; n=81$; $\mathbf{P}<0.05$ ).

\section{SPIRONOLACTONE DOSAGE}

All 67 patients received oral spironolactone in a dose of $50-400$ $\mathrm{mg}$ daily (mean $254 \mathrm{mg}$ daily) for a minimum period of four weeks (range 1-96 months; mean 11.3 months). The lower doses were used when the resultant hypotensive response was satisfactory.

Of the 67 patients 19 continue with spironolactone only, two stopped the drug because of side effects, two died while taking this treatment, four are currently lost to follow-up, and in two cases other hypotensive agents were eventually introduced. In the remaining 38 spironolactone was withdrawn before adrenal surgery.

\section{ADRENAL SURGERY}

Of the 38 who came to adrenal surgery, 32 have so far been adequately followed subsequently. One patient died postoperatively from retroperitoneal haemorrhage, one defaulted, and the remaining four have not yet been fully assessed since operation.

The adrenocortical histology in 32 of the treated cases was reviewed independently by Professor T. Symington and Dr. A. Munro Neville, using histological criteria and methods described previously (Ferriss et al., 1970). Twenty-one of these 32 patients were found to have a unilateral adrenocortical adenoma; no adenoma was found in the other 11 .

\section{EFFECT OF SPIRONOLACTONE ON BLOOD PRESSURE}

In the series as a whole a highly significant fall in mean systolic and diastolic pressure (from $201 / 122$ to $159 / 101 ; P<0.001$ ) was evident three to five weeks after the introduction of spironolactone (Fig. 1; see also Table). A further small fall in mean systolic and diastolic pressure was seen at two to three months, but thereafter little further change was seen. No evidence of escape of blood pressure from control was seen in any patient in up to eight years of therapy. Diastolic pressure fell to 95 $\mathrm{mm} \mathrm{Hg}$ or less, or by $20 \mathrm{~mm} \mathrm{Hg}$ or more, in 52 of the 67 patients. The mean pretreatment blood urea in the 15 patients whose blood pressure responded poorly on this arbitrary basis was $41.0 \mathrm{mg} / 100 \mathrm{ml}$, significantly higher than the mean in the 52 who responded well $(32.1 \mathrm{mg} / 100 \mathrm{ml} ; t=2.86 ; \mathrm{P}<0.01)$. In only four individuals was no effect on arterial pressure apparent (change in mean diastolic less than $10 \mathrm{~mm} \mathrm{Hg}$ ). The mean

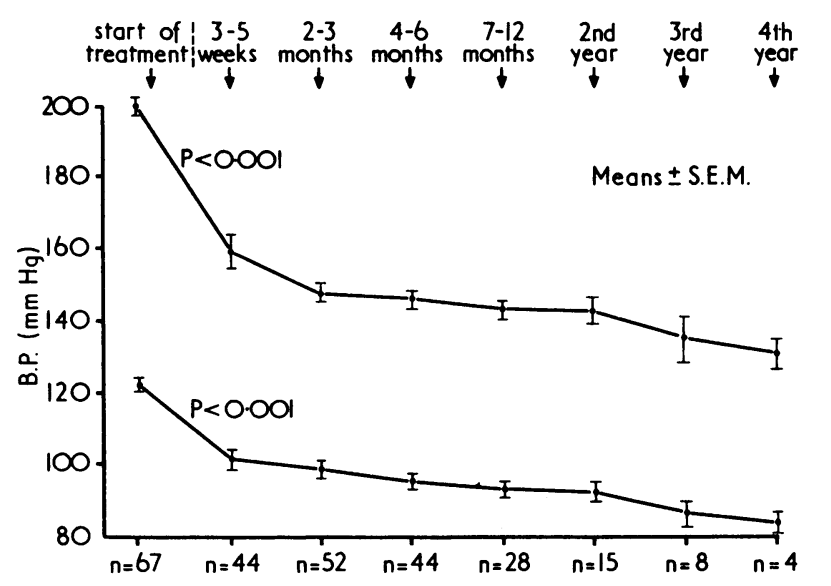

FIG. 1-Whole series. Mean systolic and diastolic blood pressures before and at varying intervals after the start of spironolactone treatment. The number at varying intervals after the start of spironolact 
Effects of Spironolactone

\begin{tabular}{|c|c|c|c|c|c|}
\hline Observation & $\begin{array}{c}\text { Before } \\
\text { Treatment }\end{array}$ & $\underset{\text { Spironolactone }}{\text { During }}$ & No. of Pairs & $t$ & $\mathbf{P}$ \\
\hline 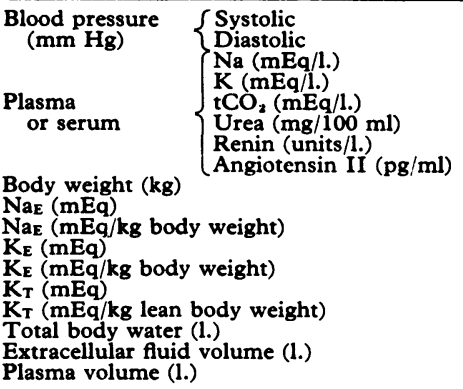 & $\begin{array}{l}201(2.94) \\
122(1 \cdot 48) \\
142 \cdot 3(0 \cdot 356) \\
3.1(0 \cdot 087) \\
28 \cdot 5(0 \cdot 494) \\
35 \cdot 2(1 \cdot 58) \\
4 \cdot 8(0 \cdot 34) \\
5.3(0.57) \\
65 \cdot 36(1.90) \\
2,967(110) \\
45.56(1.35) \\
2189(136) \\
33.53(1 \cdot 867) \\
2,256(219) \\
49 \cdot 13(1.562) \\
37.9(1 \cdot 83) \\
19.3(0.79) \\
3.07(0.21)\end{array}$ & $\begin{array}{l}149(3.33) \\
97(1 \cdot 84) \\
138 \cdot 3(0 \cdot 355) \\
4.5(0.052) \\
23 \cdot 6(0 \cdot 393) \\
49.8(2 \cdot 77) \\
19.4(1 \cdot 97) \\
43.2(7.7) \\
63.82(1 \cdot 81) \\
2,494(99) \\
39 \cdot 61(1 \cdot 17) \\
2386(129) \\
37.27(1 \cdot 604) \\
2,951(342) \\
61.27(1.246) \\
35.3(1.95) \\
16.6(0.82) \\
2.80(0.24)\end{array}$ & $\begin{array}{r}67 \\
67 \\
56 \\
57 \\
49 \\
54 \\
29 \\
3 \\
33 \\
21 \\
21 \\
21 \\
21 \\
3 \\
3 \\
15 \\
13 \\
10\end{array}$ & $\begin{aligned} 15 \cdot 82 \\
15 \cdot 36 \\
8 \cdot 42 \\
12 \cdot 78 \\
9 \cdot 14 \\
8 \cdot 57 \\
7.99 \\
5 \cdot 27 \\
2 \cdot 23 \\
6 \cdot 43 \\
4 \cdot 85 \\
2 \cdot 097 \\
2 \cdot 508 \\
4 \cdot 637 \\
12 \cdot 46 \\
3 \cdot 654 \\
4 \cdot 305 \\
2 \cdot 267\end{aligned}$ & $\begin{array}{l}<0.001 \\
<0.001 \\
<0.001 \\
<0.001 \\
<0.001 \\
<0.001 \\
<0.001 \\
<0.05 \\
<0.05 \\
<0.001 \\
<001 \\
<0.025 \\
<0.05 \\
<0.01 \\
<0.01 \\
<0.01 \\
<0.05\end{array}$ \\
\hline
\end{tabular}

Mean values shown ( \pm S.E. of mean in parentheses). All comparisons by paired $t$ test.

pretreatment blood urea in these four was even higher $(56 \cdot 2$ $\mathrm{mg} / 100 \mathrm{ml}$ ) and significantly different from the mean for the whole series $(t=3.6 ; \mathrm{P}<0.001)$.

It has been noted that in some subjects higher blood pressure may be recorded at the initial visit to the outpatient department than subsequently (see Pickering et al., 1961; Pickering, 1968; Dunne, 1969). This phenomenon was considered unlikely to contribute to the fall in blood pressure observed here during spironolactone treatment for the following reasons. Firstly, 12 patients of the series were seen repeatedly in the clinic before the introduction of spironolactone. In these no fall in either mean systolic or diastolic pressure was observed up to three months. Secondly, in six patients spironolactone was temporarily withdrawn after good control of blood pressure had been achieved (mean systolic $136 \pm$ S.E. of mean $9 \mathrm{~mm} \mathrm{Hg}$; mean diastolic $91 \pm 6$ during the final month of treatment). One month later the mean systolic pressure had increased to $175 \pm$ $10 \mathrm{~mm} \mathrm{Hg}(t=2.93 ; \mathrm{P}<0.02)$ and mean diastolic to $114 \pm 4$ $(t=2.63 ; \mathrm{P}<0.05)$. Three months after spironolactone had been stopped the pressures remained raised (mean systolic $181 \pm 5 ; t=2.34 ; \mathrm{P}<0.05$; mean diastolic $110 \pm 5 ; t=$ $2.34 ; \mathrm{P}<0.05)$ as compared with the last month of treatment.

A comparison of the effects of spironolactone before operation in the two groups respectively with and without adrenocortical adenoma is shown in Fig. 2. The fall in both systolic and diastolic

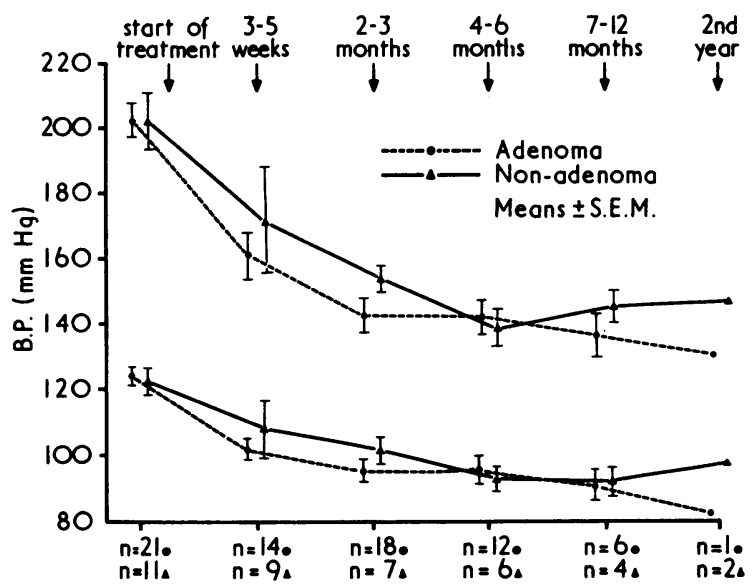

FIG. 2-Comparison of preoperative response to spironolactone in 21 patients subsequently shown to have an adrenocortical adenoma with that in 11 who did not have a tumour. The number in each group reviewed at the various intervals is shown.

pressures was highly significant in each group and at no stage was there a significant difference,jn response between the patients with and those without adrenocortical adenoma. As mentioned above, four patients showed no appreciable response. Two of these harboured an adenoma, the other two did not.

\section{EFFECT ON ELECTROLYTE CONCENTRATIONS}

Spironolactone treatment corrected plasma electrolyte abnormalities in every case, regardless of the hypotensive response. The mean changes in the series are summarized in the Table, which shows a highly significant mean increase in plasma (or serum) potassium, with a significant decrease in plasma sodium and total carbon dioxide $\left(\mathrm{tCO}_{2}\right.$ ) concentrations. In some instances overcorrection occurred. Thus plasma potassium rose to $6 \mathrm{mEq} / \mathrm{l}$. or higher during treatment in three patients. Two of these had raised blood urea levels before therapy (range $62-90 \mathrm{mg} / 100 \mathrm{ml}$ ). In the third the mean pretreatment blood urea was $28.8 \mathrm{mg} / 100 \mathrm{ml}$ (range $26-35 \mathrm{mg} / 100 \mathrm{ml}$ ). Less pronounced hyperkalaemia $(5.5-5.9 \mathrm{mEq} / \mathrm{l}$.) was seen during treatment in a further five patients, in two of whom blood urea levels were initially slightly raised (range $45-50 \mathrm{mg} / 100 \mathrm{ml}$ ). Hyperkalaemia resolved in all eight of these patients when the dose of spironolactone was reduced or stopped.

\section{EFFECT ON BODY WEIGHT AND COMPOSITION}

As shown in the Table, spironolactone treatment was accompanied by significant reductions in body weight, total body water, extracellular fluid volume, and plasma volume. A highly significant reduction in total exchangeable sodium ( $\left.\mathrm{Na}_{\mathrm{E}}\right)$ was also apparent, whether expressed in absolute terms or as a proportion of body weight. At the same time the total exchangeable potassium $\left(\mathrm{K}_{\mathrm{E}}\right)$ rose, this increase achieving a higher degree of statistical significance when expressed in relation to body weight than in absolute terms. In the three subjects in whom total body potassium (as opposed to $\mathrm{K}_{\mathrm{E}}$ ) was measured before and during treatment, a highly significant increase was similarly observed.

\section{EFFECT ON PLASMA UREA}

As shown in the Table, a marked increase in mean plasma urea concentration occurred with spironolactone treatment. Although, as mentioned above, the highest levels during therapy were seen in patients already with evidence of renal impairment, in some instances abnormally high values might also be induced in subjects with initially normal plasma urea. As detailed above higher mean pretreatment plasma urea levels were found in the patients whose hypotensive response to spironolactone was poor than in those in whom it was good.

\section{EFFECT ON RENIN AND ANGIOTENSIN II}

Spironolactone treatment resulted in an increase in plasma renin concentration from initially low values to levels within, 
and in some instances above, the normal range (see Table). A significant increase was similarly seen in plasma angiotensin II during treatment (see Table).

\section{EFFECT ON ALDOSTERONE SECRETION}

In one patient of the present series, who was subsequently found to have an adrenocortical adenoma, aldosterone secretion rate measured in the tenth month of spironolactone therapy (dose $300 \mathrm{mg} /$ day) was $1,222 \mu \mathrm{g} / 24$ hours, compared with a value of $1,140 \mu \mathrm{g}$ before treatment (Brown et al., 1965). Another patient, also with an adenoma, had an aldosterone secretion rate of $589 \mu \mathrm{g} / 24$ hours before treatment, compared with $500 \mu \mathrm{g} / 24$ hours in the fifth month of spironolactone in a dose of $300 \mathrm{mg}$ daily. Within the limits of experimental error, the values during treatment in these two patients are unchanged.

Plasma aldosterone concentration was measured in only four cases of the series during spironolactone treatment. In three of these there was a distinct.increase (from 30 to $55 \mathrm{ng} / 100 \mathrm{ml}$ in a patient with an adenoma, from 37 to $85 \mathrm{ng}$ in a man with bilateral micronodular hyperplasia, and from 28 to $66 \mathrm{ng}$ in a patient not yet operated on). In the fourth patient, in whom plasma aldosterone was initially only slightly raised (26 ng/ $100 \mathrm{ml}$ ), the value obtained during treatment was at the uppermost part of the normal range $(17 \mathrm{ng} / 100 \mathrm{ml})$. No adenoma was found at subsequent operation in this woman.

\section{COMPARISON OF SPIRONOLACTONE AND SURGERY}

In the 32 patients subjected to surgery there was good correlation between the preoperative hypotensive response achieved by spironolactone and that following operation (correlation for systolic fall $r=0.657, P<0.001$; for diastolic $r=0.544$, $P<0.01)$. Indeed, in only one of the 32 patients was a marked discrepancy apparent. In this woman there was no appreciable preoperative response to spironolactone, although after bilateral adrenalectomy there was a substantial change (fall in mean diastolic pressure $38 \mathrm{~mm} \mathrm{Hg}$ )

Despite the good correlation overall, and the one discrepant patient, spironolactone generally produced a slightly better hypotensive response than did adrenal surgery. This is borne out statistically, the regression line for the data deviating significantly in favour of the response to spironolactone (variance ratio for diastolic readings $=10.55 ; P<0.01$ ).

Fig. 3 shows the hypotensive response to spironolactone and to subsequent surgery in five subjects independently verified by the two pathologists as being without adenoma, and all of whom

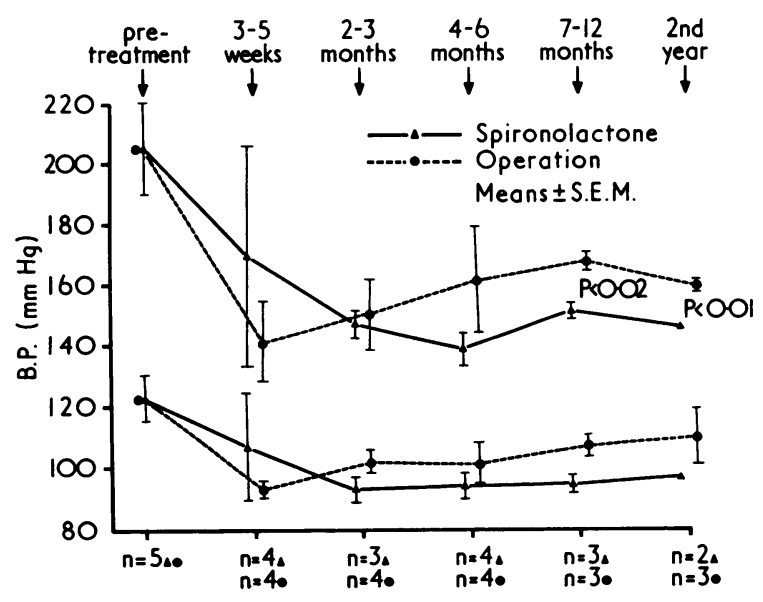

FIG. 3-Comparison in five patients eventually shown not to have an adenoma of the effect of preoperative spironolactone on blood pressure with that of of the effect of preoperative spironolactone on blood pressure with that of
subsequent surgery. Mean systolic pressure significantly lower during spironolactone treatment at 7-12 months, and in second year. All five shown to have normal plasma aldosterone levels after surgery. were shown to have normal plasma aldosterone levels after operation. Each form of treatment produced significant reductions of both systolic and diastolic pressure. As can be seen, surgery was again generally slightly less effective in lowering both systolic and diastolic pressure than was spironolactone, and the mean systolic pressures were, as shown, significantly different 7-24 months after the start of the two regimens.

Fig. 4 compares, in the 32 operated patients, the changes in
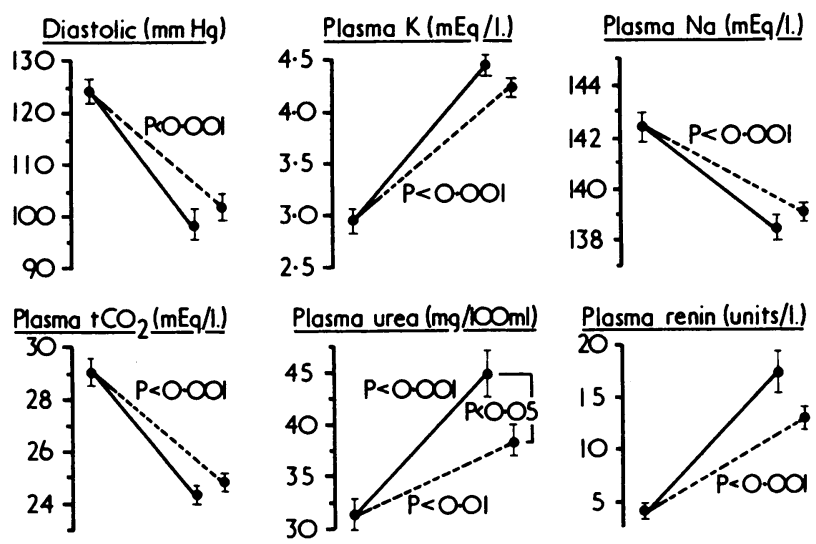

FIG. 4 - Comparison in the 32 operated patients of mean preoperative changes induced by spironolactone (continuous lines) with those subsequent to surgery (broken lines) (means \pm standard error of means). All readings after four weeks. Differences in mean changes were significant only for plasma urea $(P<0.05)$.

plasma concentrations of electrolytes, urea, and renin induced before operation by spironolactone with those following surgery. Both forms of therapy produced highly significant changes in all these variables, with again a slight but consistent tendency for spironolactone to have the greater effect. However, only in the case of the increase in plasma urea was there a significant difference between the spironolactone-induced and the surgicallyinduced change $(P<0.05)$.

\section{SIDE-EFFECTS INDUCED BY SPIRONOLACTONE}

The side-effects encountered in this series were as listed elsewhere (Brown et al., 1969a, 1971b), and included gynaecomastia, epigastric discomfort, Raynaud's phenomenon, menstrual irregularities, lassitude, cutaneous pigmentation, excessive sweating, and, in one instance, impotence. These unwanted effects were generally minor and in only two of the present 67 cases were they severe enough to lead to withdrawal of the drug.

\section{Discussion}

As in earlier reports from this unit (Brown et al., 1969a; Fraser et al., 1969; Robertson et al., 1972), a significant (although not particularly close) inverse correlation was found in the patients of the present series between concurrent measurements of plasma renin and aldosterone concentrations. This relationship deserves emphasis, since the low plasma renin concentrations of this syndrome were within a very narrow range and were also, by virtue of their lowness, subject to some technical imprecision in measurement. The inverse correlation found therefore indicates, firstly, that the excessive aldosterone production was not mediated by renin, and, secondly, that the low plasma renin was a direct or indirect consequence of the rise in plasma aldosterone.

The present results confirm and extend earlier reports of the predictive value of spironolactone on the subsequent hypotensive effect of adrenal surgery in patients with adrenocortical adenomata (Spark and Melby, 1968; Brown et al., 1969a, 1970b, 
1970c, 1971b). On present evidence a poor response to both forms of therapy is more likely if the plasma urea level before treatment is raised.

It is clear that a good hypotensive effect is achieved also in patients with hyperaldosteronism and low plasma renin, but without adrenal adenomata confirming the observations of Crane and Harris (1970) on two patients without tumours.

An earlier report (Spark and Melby, 1968) raised the possibility of spironolactone being ineffective in cases of this variety. The present findings indicate that Spark and Melby's cases were atypical, a conclusion of especial relevance to surgical treatment. While our surgical results in patients without adenoma seem to be better than those in several reports from other centres (Katz, 1967; Laragh et al., 1967; Spark and Melby, 1968; Baer et al., 1970; Biglieri et al., 1970), spironolactone is, on present evidence, superior, and thus offers a rational alternative form of therapy to the extensive bilateral adrenal resection otherwise indicated. Spironolactone is especially attractive as long-term or definitive therapy in elderly patients, or in those otherwise unsuited or unwilling to undergo surgery. It thus becomes of some practical importance to be able to distinguish cases with and without adenoma before operation if possible.

Several authors have commented on the general tendency for the biochemical abnormalities to be less severe in the patients without adenomata (Distler et al., 1969; Baer et al., 1970; Biglieri et al., 1970; Ferriss et al., 1970). We have used the statistical technique of quadric analysis, utilizing these biochemical differences, to predict before operation whether a given patient is or is not likely to harbour an adrenocortical tumour (Ferriss et al., 1970; Aitchison et al., 1971). With this approach it is now possible to avoid operation in patients without adenoma, using long-term spironolactone as alternative treatment.

The effectiveness of high-dosage spironolactone in essential hypertension is still undecided, although there is little doubt that modest doses (100-150 mg/day) will produce small reductions in arterial pressure similar to those effected by benzothiadiazines (see Hollander et al., 1960; Georgopoulos et al., 1961; Cranston and Juel-Jensen, 1962; Grieble and Johnson, 1962; Conway and Palmero, 1963; Wolf et al., 1966; Winer et al., 1968; Crane and Harris, 1970). The problem is complex, since spironolactone can produce substantial blood pressure reduction in syndromes of mineralocorticoid excess not associated with an increase in circulating aldosterone. These include increased production of 18-hydroxydeoxycorticosterone (Melby et al., 1971) and of deoxycorticosterone (Brown et al., 1972a). It is therefore necessary to exclude mineralocorticoid excess so far as possible in any patient with hypertension showing a marked fall in blood pressure on spironolactone (Spark and Melby, 1971; Crane et al., 1972).

The spironolactone-induced increases in total exchangeable or total body potassium, with concurrent decreases in total body water, extracellular fluid and plasma volumes, and in total exchangeable sodium confirm our earlier findings in a detailed study of a single patient (Brown et al., 1965). Increases in plasma potassium sufficient to cause concern were observed usually only where there was evidence of renal functional impairment. Nevertheless, potassium supplements are not required when spironolactone is being administered, and may indeed be dangerous.

The increases in plasma urea during treatment seem attributable, at least in part, to the concomitant shrinkage in plasma and extracellular fluid volumes. The additional possibility that spironolactone induces increased tissue catabolism cannot be excluded, but does not receive very forceful support from the present data. The mean fall in body weight, although significant, was not great, nor did the plasma $\mathrm{tCO}_{2}$ concentration fall to particularly low levels (see Table).

The action of spironolactone in raising plasma renin and angiotensin II concentrations from very low to normal or high values confirms our earlier reports (Brown et al., 1963a, 1964a, 1964b,
1965), and is also in accord with the similar studies of plasma renin activity by Spark and Melby (1968) and Morimoto et al. (1970). The occasional abnormally high values observed during treatment indicate relative sodium depletion. The effect of dietary sodium deprivation in causing increases in plasma renin concentration was reported several years ago (Brown $e t$ al., 1963b, 1964d). More recently, evidence has been produced that potassium depletion may also stimulate increases in renin (Veyrat et al., 1967a, 1967b; Brunner et al., 1970). The present evidence confirms earlier work (Brown et al., 1965) that any such effect of potassium on renin is, however, relatively minor, at least in these patients, and is readily overwhelmed by converse changes in sodium balance during spironolactone treatment.

In the two patients of the present series in whom aldosterone secretion rate was measured before and during therapy no appreciable change occurred. This failure of aldosterone secretion to increase despite several simultaneous potential stimuli (increase in plasma renin, angiotensin II, and potassium concentrations and in $K_{E}$, with decrease in plasma sodium and $\mathrm{Na}_{\mathrm{E}}$ ) indicates autonomy of the adrenocortical adenomata in these two subjects, with the remainder of the adrenal cortex making only a minor contribution to aldosterone secretion even during treatment. The rather different findings of Mobley et al. (1962) and Spark and Melby (1968) suggest a variable degree of adrenal autonomy in different patients.

A distinct increase in plasma aldosterone concentration was observed in three of the four patients of the present series in whom the measurement was made both before and during treatment. However, changes in plasma aldosterone concentration during spironolactone therapy probably do not accurately reflect changes in aldosterone secretion, since the associated increase in circulating renin and angiotensin II would diminish hepatic blood flow (De Bono et al., 1963) and so tend to impair aldosterone metabolic clearance (Bougas et al., 1964). Moreover, the associated shrinkage in extracellular fluid and plasma volume (see Table) would also enhance plasma aldosterone concentration.

The prognostic value of spironolactone in indicating the likely hypotensive effect of adrenal surgery has already been emphasized. This apart, a preoperative course of spironolactone will, by correcting the hypertension and electrolyte abnormalities, render surgery safer. Possibly also, by activating the reninangiotensin system, it may, at least in some patients, make aldosterone deficiency in the immediate postoperative phase less likely (Morimoto et al., 1970). Our usual practice is to give high dosage spironolactone to within 24 hours of surgery, and then discontinue the drug. In this connexion possible confusion with plasma "cortisol" should be borne in mind if the method of Mattingly (1962) is used for the estimation of plasma 11hydroxycorticosteroids (see Brown et al., 1971b, 1972d; Robertson et al., 1972).

Alternatively, in patients unwilling or unsuitable to undergo surgery (and particularly in those cases in which quadric analysis indicates that an adrenocortical adenoma is unlikely to be present), long-term or definitive treatment with spironolactone may be used. Silen et al. (1966) and Brooks et al. (1972) suggested that spironolactone should not be given long-term because of the danger of inadvertently overlooking an aldosteronesecreting carcinoma. In our view the risks of confusing hyperaldosteronism due to adrenal carcinoma with that associated with a benign adenoma or hyperplasia are slight, and not sufficient to preclude long-term spironolactone therapy in selected instances (Brown et al., 1972b).

It is emphasized that in this series of 67 patients side effects were usually minor, and only rarely necessitated withdrawal of the drug. We thus differ from the findings of Spark and Melby (1968) that the side effects rendered long-term therapy intolerable in most patients (see also British Medical fournal, 1969; Brown et al., 1969b). Our experience indicates that spironolactone compares favourably with most drugs used in the treatment of hypertension in this respect. Nineteen of the present 67 patients have not been subjected to surgery and are 
currently maintained on treatment with spironolactone. One woman (see Brown et al., 1963a, 1964a) has received continuous therapy for more than eight years, with good control of the arterial pressure and without side effects.

We are grateful to Professor W. S. Peart for allowing us access to the records of patients originally studied at St. Mary's Hospital, London; to Mr. K. Owen and Professor A. W. Kay, who performed adrenal surgery in most of the operated cases; to Professor T. Symington, Dr. A. Munro Neville and Dr. R. A. Parker for histological interpretations; to Dr. K. Boddy and Dr. Priscilla King for total body potassium measurements; and to the many physicians who referred cases to us.

\section{References}

Aitchison, J., et al. (1971). American Heart fournal, 82, 660.

Baer, L., Sommers, S. C., Krakoff, L. R., Newton, M. A., and Laragh, J. H. (1970). Circulation Research, 26, 27, Suppl. No. 1, 203.

Bartter, F. C. (editor) (1960). The Clinical Use of Aldosterone Antagonists. Springfield, Illinois, Thomas.

Biglieri, E. G., Schambelan, M., Slaton, P. E., and Stockigt, J. R. (1970). Circulation Research, 26, 27, Suppl. No. 1, p. 195.

Boddy, K. (1967). Physics in Medicine and Biology, 12, 43.

Bolte, E., et al. (1958). Canadian Medical Association fournal, 79, 881.

Bougas, J., et al. (1964). In Aldosterone. An International Symposium, ed. E. E. Baulieu and P. Robel, p. 25. Oxford, Blackwell Scientific.

British Medical fournal, 1969, 3, 427. Brooks, R. V., Felix-Davies, D., Lee, M. R., and Robertson, P. W. (1972).
British Medical Fournal, 1, 220.

Brown, J. J., Davies, D. L., Lever, A. F., and Robertson, J. I. S. (1963a). In Hypertension (Boerhaave Course), ed. J. de Graeff, pp. 44, 216. Leiden, University of Leiden Press.

Brown, J. J., Davies, D. L., Lever, A. F., and Robertson, J. I. S. (1963b). Lancet, 2, 278.

Brown, J. J., Davies, D. L., Lever, A. F., and Robertson, J. I. S. (1964a). Canadian Medical Association fournal, 90, 201.

Brown, J. J., Davies, D. L., Lever, A. F., Peart, W. S., and Robertson, J. I. S. (1964b). British Medical fournal, 2, 1636.

Brown, J. J., Davies, D. L., Lever, A. F., Robertson, J. I. S., and Tree, M. (1964c). Biochemical fournal, 93, 594.

Brown, J. J., Davies, D. L., Lever, A. F., and Robertson, J. I. S. (1964d). fournal of Physiology, 173, 408 .

Brown, J. J., Davies, D. L., Lever, A. F., Peart, W. S., and Robertson, J. I. S. (1965). Fournal of Endocrinology, 33, 279.

Brown, J. J., et al. (1968a). Lancet, 2, 55.

Brown, J. J., et al. (1968b).Quarterly fournal of Medicine, 37, 97.

Brown, J. J., Lever, A. F., and Robertson, J. I. S. (1968c). Annals of Internal Medicine, 68, 1152 .

Brown, J. J., et al. (1969a). Proceedings of the Royal Society of Medicine, 62, 1258 .

Brown, J. J., et al. (1969b). British Medical fournal, 4, 688.

Brown, J. J., et al. (1970a). British Medical Fournal, 2, 18.

Brown, J. J., et al. (1970b). Actualités Néphrologiques de l'Hôpital Necker, p. 131. Paris, Editions Medicales Flammarion.

Brown, J. J., et al. (1970c).Quarterly Fournal of Medicine, 39, 631

Brown, J. J., et al. (1971a). In Seventh Symposium on Advanced Medicine (Royal College of Physicians of London), ed. I. A. D. Bouchier, p. 265. London, Pitman Medical.

Brown, J. J., Ferriss, J. B., Fraser, R., Lever, A. F., and Robertson, J. I. S. (1971b). In The Medical Uses of Spironolactone, ed. G. M. Wilsr $\mathrm{n}$, p. 27. Amsterdam, Excerpta Medica.
Brown, J. J., et al. (1972a). In The Renin-Angiotensin-Aldosterone-Sodium System and Hypertension, ed. J. Genest. Berlin, Springer. Brown, J. J., Ferriss, J. B., Fraser, R., Lever, A. F., and Robertson, J. I. S.
(1972b). British Medical fournal, 1, 686.

Brown, J. J., Fraser, R., Lever, A. F., and Robertson, J. I. S. (1972c). British Medical fournal, $1,397$.

Brown, J. J., Fraser, R., Lever, A. F., and Robertson, J. I. S. (1972d). Clinics in Endocrinology and Metabolism. In press.

Brunner, H. R., Baer, L., Sealey, J. E., Ledingham, J. G. G., and Laragh, J. M. (1970). Fournal of Clinical Investigation, 49, 2128.

Conn, J. W., et al. (1958). Fournal of Laboratory and Clinical Medicine, 52,

Conway, J., and Palmero, H. (1963). Archives of Internal Medicine, 111, 203. Cope, C. L., Nicholis, G., and Fraser, R. (1961). Clinical Science, 21, 367. rane, M. G., and Harris, J. J. (1970). American Fournal of the Medical Sciences, 260, 311 .

Crane, M. G., Harris, J. J., and Johns, V. J. (1972). American fournal of Medicine, 52, 457.

Cranston, W. I., and Juel-Jensen, B. E. (1962). Lancet, 1, 1161.

De Bono, E., et al. (1963). Clinical Science, 25, 123.

Distler, A., et al. (1969). Klinische Wochenschrift, 47, 688

Dunne, J. F. (1969). Lancet, 1, 391, 629.

Düsterdieck, G., and McElwee, G. (1971). European fournal of Clinical Investigation, 2, 32.

Ferriss, J. B. et al. (1970). Lancet, 2, 995.

Flanagan, M. J., Gantt, C. J., and MacDonald, J. M. (1962). Fournal of Urology, 88, 111

Fraser, R., Brown, J. J., Chinn, R. H., Lever, A. F., and Robertson, J. I. S. (1969). Scottish Medical fournal, 14, 420.

Fraser, R., and James, V. H. T. (1968). Fournal of Endocrinology, 40, 59.

Georgopoulos, A. J., Dustan, H. J., and Page, I. H. (1961). Archives of Internal Medicine, 108, 389.

Grieble, H. G., and Johnson, L. C. (1962). Archives of Internal Medicine, $110,26$.

Hollander, W., Chobanian, A. V., and Williams, R. W. (1960). In The Clinical Use of Aldosterone Antagonists, ed. F. C. Bartter, p. 169. Springfield, Illinois, Thomas.

Katz, F. H. (1967). Annals of Internal Medicine, 67, 1035.

Kistler, H., Shelley, T. F., and Frawley, T. (1959). Clinical Research Proceedings, 7, 254.

Laragh, J. H., Ledingham, J. G. G., and Sommers, S. C. (1967). Transactions of the Association of American Physicians, 80, 168.

Mattingly, D. (1962). Fournal of Clinical Pathology, 15, 374

Melby, J. C., Dale, S. L., and Wilson, B. S. (1971). Circulation Research, 28, 29, Suppl. No. 2, p. 143.

Mobley, J. E., Headstream, J. W., and Melby, J. C. (1962). Fournal of the American Medical Association, 180, 1056

Morimoto, S., Takeda, R., and Murakami, M. (1970). Fournal of Clinical Endocrinology and Metabolism, 31, 659. Pickering, G. W. (1968). High Blood Pressure, 2nd edn., London,

Pickering, G. W., Cranston, W. I., and Pears, M. A. (1961). The Treatment of Hypertension, p. 40. Springfield, Illinois, Thomas.

Robertson, J. I. S., et al. (1972). Anglo-German Medical Review, 6, 55.

Salassa, R. M., Mattox, V. R., and Power, M. H. (1958). Fournal of Clinical

Endocrinology and Metabolism, 18, 787.
Silen, W., Biglieri, E. G., Slaton, P. E., and Galante, M. (1966). Annals of Surgery, 164, 600

Spark, R. F., and Melby, J. C. (1968). Annals of Internal Medicine, 69, 685.

Spark, R. F., and Melby, J. C. (1971). Annals of Internal Medicine, 75, 831.

arazi, R. C., Dustan, H., Frohlich, E. D., Gifford, R. W., and Hoffman, G. C. (1970). Archives of Internal Medicine, 125, 835.

Veyrat, R., Brunner, H. R., Grandchamp, A., and Muller, A. F. (1967a). Acta Endocrinologica' Kobenhavn), Suppl. No. 119, p. 86.

Veyrat, R., Brunner, H. R., Manning, E. L., and Muller, A. F. (1967b) fournal d'Urologie et de Néphrologie, 73, 271.

Winer, B. M., Lubbe, W. F., and Colton, T. (1968). Fournal of the American Medical Association, 204, 775.

Wolf, R. L., et al. (1966). Fournal of the American Medical Association, 198, 1143 . 